\title{
Risk Factors, Clinical Features, and Radiographic Abnormalities of Feet in Diabetic Patients
}

\author{
Jayachandraํㅜ Harsha Vishwanath Patel ${ }^{2}$, Rajendra Prasad Honnaiah ${ }^{3}$ \\ 1, 2,3 Department of General Medicine, Bangalore Medical College and Research Institute, \\ Bengaluru, Karnataka, India.
}

\section{ABSTRACT}

\section{BACKGROUND}

Foot problems are a leading cause of hospitalization for patients having diabetes mellitus all over the world. Foot ulcers in diabetes precede $85 \%$ of nontraumatic lower-extremity amputations. Fifteen percent develop foot ulcers during their lifetime. Individuals who develop foot ulcers have a decreased health-related quality of life and consume a lot of healthcare resources. Foot abnormalities is a frequently missed diagnosis and a focus in this area of medical education has never been optimal despite its frequency of presentation. In this study, we wanted to determine clinical and radiographic foot abnormalities in diabetic patients.

\section{METHODS}

A cross-sectional study was carried out on 180 type 2 diabetic patients diagnosed as per ADA definition of diabetes, they were categorized into three groups, the first consisted of 60 diabetic patients without neuropathy or foot ulcers, the second had 60 diabetic patients with neuropathy and the third had 60 diabetic patients with both neuropathy and foot ulcer. Based on the clinical examination of the foot and foot X-ray oblique and lateral view of the affected feet along with other relevant investigations were obtained and analysed using descriptive and inferential statistical analysis.

\section{RESULTS}

We observed that poor glycaemic control and duration of diabetes were important risk factors for foot complications in diabetic patients which were statistically significant. Among patients with only diabetes, $3.3 \%$ had HbA1c less than 6, $35 \%$ had HbA1c between $6-9$ and $61.7 \%$ with HbA1c of more than 9. Among the patients with diabetes and neuropathy, $1.7 \%$ of people had Hba1c of less than 6,20 $\%$ with Hba1c between 6 - 9 and $78.3 \%$ with Hba1c of more than 9. In patients who had diabetes and neuropathy with foot ulcers, $6.7 \%$ had HbA1c of less than 6 , among the same cohort $8.3 \%$ had HbA1c between 6 - 9 and $85 \%$ had HbA1c above 9. The prevalence of various radiological abnormalities of the foot was more common in diabetic patients with both neuropathy and foot ulceration (group lll) (83.3 \%). The most common abnormality as observed from our study was Osteopenia with osteoporotic changes seen in 36.7 \% of Group III patients VS 16.7 $\%$ of Group II (patients with diabetes and neuropathy ) and only in $10 \%$ of Group I patients (patients with diabetes without any complications). Vascular calcifications were observed in $26.7 \%$ VS $16.7 \%$ VS $6.7 \%$ in Group III, Group II, Group I respectively. Periosteal reactions were also more common in Group III patients (6.7 $\%)$. Subluxation of $2^{\text {nd }}, 3^{\text {rd }}, 4^{\text {th }}$, and $5^{\text {th }}$ metatarsals was observed only in $3.3 \%$ of Group III patients.

\section{CONCLUSIONS}

Diabetic foot is one of the most devastating complications of diabetes. Preventing the diabetic foot should be the first priority. This can be achieved by identifying the high-risk individuals with the above said risk factors by proper clinical examination and use of foot X-ray.

\section{KEY WORDS}

Diabetic Foot, Foot Problems, Foot Infections.
Corresponding Author: Dr. Harsha Vishwanath Patel, \#33, Sri Lakshmi Venkateshwara nilaya, Gopal Krishna Layout, Yadalam Nagara, Subramanyapura Main Road, Bengaluru - 560061, Karnataka, India. E-mail: hvpatel18@gmail.com

DOI: $10.14260 /$ jemds/2021/726

How to Cite This Article: Jayachandra, Patel HV, Honnaiah RP. Risk factors, clinical features, and radiographic abnormalities of feet in diabetic patients. $J$ Evolution Med Dent Sci 2021;10(41):35823586, DOI: 10.14260/jemds/2021/726

Submission 12-08-2020,

Peer Review 08-04-2021,

Acceptance 15-04-2021,

Published 11-10-2021.

Copyright (C) 2021 Jayachandra et al. This is an open access article distributed under Creative Commons Attribution License [Attribution 4.0 International (CC BY 4.0)] 


\section{BACKGROUND}

Foot infections in diabetic patients are associated with significant morbidity and mortality. ${ }^{1}$ In India, diabetic foot ulcers may become more common given the fact that the prevalence of diabetes is predicted to increase by $69 \%$ in developing countries in the next 20 years. ${ }^{2}$ Nevertheless, foot problems receive less attention than other diabetic complications and it is not yet a priority of medical service in India. ${ }^{3}$ Major risk factors implicated in the development of diabetic foot infections are neuropathy, poor glycaemic control, and peripheral vascular disease. Patients with sensory neuropathy have diminished perception of pain and temperature which makes it difficult for them to recognize injury of their foot. Loss of joint position sense in diabetic patients leads to chronic, progressive, and destructive arthropathy, also called Charcot arthropathy, originally described by Charcot with respect to tables dorsalis. Diabetic neuropathic arthropathy is also called diabetic osteoarthropathy. It is hypothesised that diabetic foot ulcers are surrogate markers of more advanced microvascular and macro-vascular disease, and also contribute independently to mortality due to inflammatory sequelae. ${ }^{4}$ In a study on 85 patients presenting to a diabetic foot clinic with acute Charcot arthropathy, reported that type 2 diabetics presented in their sixth decade, with a mean duration of diabetes $13 \pm 8.1$ years. ${ }^{5}$ In a study on 561,597 diabetic patients, which mainly consisted of type 2 Diabetes showed the incidence of Charcot arthropathy as 0.12 percent. $^{6}$

Often an initial trivial trauma results in chronic foot ulcers which may later require hospitalisation adding to the financial burden of the patient. ${ }^{7}$ When we stand, an individual foot bears half of the body weight. During some instances while walking when one foot bears even one and a half times of body weight this increases further if there is any deformity or obesity. ${ }^{8}$ The callused thick edges of a wound tend to roll inwards and inhibit the growth towards the centre, making a wound non healing. ${ }^{9}$ Repeated shear stress is known to cause callus which leads to a diabetic foot ulcer. ${ }^{10}$ Most dreaded complication of a foot ulcer is limb amputation, whose incidence is 10 to 30 times more frequent in diabetics. ${ }^{11,12}$ Diabetes is implicated in 8 out of 10 non-traumatic amputations, $85 \%$ of these follow foot ulcers. ${ }^{13,14,15}$ Mortality rates after amputation range from $13 \%$ to $40 \%$ at 1 year, 35 $\%$ to $65 \%$ at 3 years, and $39 \%$ to $80 \%$ at 5 years respectively which is even worse than most malignancies. ${ }^{16}$ Iversen et al. in their study found that the occurrence of a diabetic foot ulcer was an independent predictor of mortality even at 10 years. ${ }^{17}$

The vast majority of diabetic foot-related complications resulting in amputation can be prevented by early detection and appropriate treatment of these ulcers by the primary caregiver. Relevant history, clinical examination and radiological imaging are important for the diagnosis. Plain Xray of foot and ankle can be used to evaluate the bony destruction, deformity and in case of foot infection, it can be used to evaluate the presence of soft tissue gas or any foreign bodies. ${ }^{18}$ Unfortunately, several studies have found that primary care physicians infrequently perform foot examinations in diabetic patients during routine visits to the hospital. Foot X-ray can be used for screening the extent of bone and joint involvement in high-risk patients. 19,20

\section{METHODS}

A cross-sectional study was conducted between March 2016 and April 2018 at hospitals attached to Bangalore medical college and research institute (BMCRI).

\section{Inclusion Criteria}

Type 2 diabetic patients aged above 18 years are diagnosed as per the American Diabetes Association ${ }^{21}$ definition of diabetes mellitus.

\section{Exclusion Criteria}

- Patients of type 1 diabetes mellitus,

- With a previous history of trauma to the feet.

- With congenital foot abnormalities.

- Patients with latent autoimmune diabetes in adults (LADA) and maturity onset diabetes of the young (MODY)

The following ADA definition was used for the diagnosis of type 2 diabetes mellitus -

- $\mathrm{HbA} 1 \mathrm{c} \geq 6.5 \%$.

OR

- $\quad$ Fasting plasma glucose $\geq 126 \mathrm{mg} / \mathrm{dl}(7.0 \mathrm{mmol} / \mathrm{l})$. Fasting is defined as no caloric intake for at least $8 \mathrm{~h}$.

OR

- 2-h plasma glucose $\geq 200 \mathrm{mg} / \mathrm{dl}$ (11.1 mmol / l) during an oral glucose tolerance test (OGTT). The test should be performed as described by the World Health Organization, using a glucose load containing the equivalent of $75 \mathrm{~g}$ anhydrous glucose dissolved in water.

OR

- In a patient with classic symptoms of hyperglycaemia or hyperglycaemic crisis, a random plasma glucose $\geq 200$ $\mathrm{mg} / \mathrm{dl}(11.1 \mathrm{mmol} / \mathrm{l})$.

\section{Data Collection}

A comparative three-group clinical study was carried out on type 2 diabetic patients diagnosed as per ADA definition of diabetes after obtaining written informed consent from the study subjects and approval from our institutional ethical committee. This study included a total of 180 diabetic patients who were categorized into three groups, the first consisted of 60 diabetic patients without neuropathy or foot ulcers, the second had 60 diabetic patients with neuropathy and the third had 60 diabetic patients with both neuropathy and foot ulcer based on clinical examination of the foot and foot X-ray oblique and lateral view of the affected feet along with other relevant investigations were obtained and analysed using statistical analysis. 


\section{Statistical Analysis}

Descriptive and inferential statistical analysis has been carried out in the present study. Results on continuous measurements were presented on Mean \pm SD (Min-Max) and results on categorical measurements were presented in Number (\%). Significance was assessed at $5 \%$. The following assumptions on data were made.

Assumptions - 1. Dependent variables should be normally distributed, 2. Samples drawn from the population should be random, Cases of the samples should be independent.

Student t-test (two-tailed, independent) has been used to find the significance of study parameters on a continuous scale between two groups (Intergroup analysis) on metric parameters.

Chi-square / Fisher Exact test has been used to find the significance of study parameters on a categorical scale between two or more groups, Non-parametric setting for Qualitative data analysis. Fisher Exact test was used when cell samples were very small.

\section{Significant Figures \\ + Suggestive significance (P value: $0.05<\mathrm{P}<0.10$ ) \\ * Moderately significant (P value: $0.01<\mathrm{P} \leq 0.05$ ) \\ ** Strongly significant ( $\mathrm{P}$ value: $\mathrm{P} \leq 0.01$ )}

\section{Statistical Software}

The Statistical software namely SPSS 18.0, and $R$ environment ver.3.2.2 were used for the analysis of the data and Microsoft Word and Excel have been used to generate graphs, tables. $22,23,24,25$

\section{RESULTS}

The study consisted of 180 patients with the sex ratio Male: Female - 91:89 (Table 1). Patients being categorised as mentioned earlier into three groups. Group 1 consisted of 60 diabetic patients without neuropathy and foot ulcer (M: F 35:25, Mean age was 52.88 years), Group 2 consisted of 60 diabetic patients with neuropathy (M: F - 29:31, mean age was 59.30 years), Group 3 consisted of 60 diabetic patients with both neuropathy and foot ulceration (M: F - 27:33, Mean age was 54.48 years).

\begin{tabular}{|ccccc|}
\hline Gender & Group I & Group II & Group III & Total \\
Female & $25(41.7 \%)$ & $31(51.7 \%)$ & $33(55 \%)$ & $89(49.4 \%)$ \\
Male & $35(58.3 \%)$ & $29(48.3 \%)$ & $27(45 \%)$ & $91(50.6 \%)$ \\
Total & $\mathbf{6 0}(\mathbf{1 0 0} \%)$ & $\mathbf{6 0}(\mathbf{1 0 0} \%)$ & $\mathbf{6 0}(\mathbf{1 0 0} \%)$ & $\mathbf{1 8 0}(\mathbf{1 0 0} \%)$ \\
\hline \multicolumn{5}{c|}{ Table 1. Gender Distribution of Patients Studied } \\
\hline $\mathrm{P}=0.315$, Not Significant, chi-square Test \\
\hline
\end{tabular}

As we can see from Table 2 mean age in Group 1 was $52.88 \pm 11.84$, in Group 2 was $59.30 \pm 11.85$ and in Group 3 was $54.48 \pm 10.72$, Mean average age of the subjects in the study was 55.56 years and patients belonging to Group 1 were younger than that of other two groups $\left(\mathrm{P}=0.007^{* *}\right.$, Significant, Student t-test).

We can infer from Table 3 that the majority of the patients in the study had disease duration between 1 and 10 years and surprisingly patients with a duration of disease more than 20 years were found in Group 1 and as expected patients with newly diagnosed diabetes were more in Group $1\left(\mathrm{P}=0.027^{*}\right.$, Significant, Fisher Exact Test).

In our study 133 patients had a disease history between 1 and 10 years, 39 patients had a disease duration from 11 to 20 years, only 2 had a disease duration between 21 and 30 years and 6 were newly diagnosed cases of diabetes.

\begin{tabular}{|c|c|c|c|c|}
\hline Age in years & Group I & Group II & Group III & Total \\
\hline$<30$ & $1(1.7 \%)$ & $0(0 \%)$ & $0(0 \%)$ & $1(0.6 \%)$ \\
\hline $30-40$ & 7 (11.7\%) & $5(8.3 \%)$ & $6(10 \%)$ & $18(10 \%)$ \\
\hline $41-50$ & $19(31.7 \%)$ & $11(18.3 \%)$ & $17(28.3 \%)$ & $47(26.1 \%)$ \\
\hline $51-60$ & $21(35 \%)$ & $15(25 \%)$ & $20(33.3 \%)$ & 56 (31.1\%) \\
\hline $61-70$ & $8(13.3 \%)$ & $20(33.3 \%)$ & $14(23.3 \%)$ & $42(23.3 \%)$ \\
\hline $71-80$ & $3(5 \%)$ & $9(15 \%)$ & $3(5 \%)$ & $15(8.3 \%)$ \\
\hline$>80$ & $1(1.7 \%)$ & $0(0 \%)$ & $0(0 \%)$ & $1(0.6 \%)$ \\
\hline Total & 60 (100\%) & 60 (100\%) & $60(100 \%)$ & $180(100 \%)$ \\
\hline Mean \pm SD & $52.88 \pm 11.84$ & $59.30 \pm 11.85$ & $54.48 \pm 10.72$ & $55.56 \pm 11.74$ \\
\hline \multicolumn{5}{|c|}{ Table 2. Age Distribution of Patients Studied } \\
\hline
\end{tabular}

\begin{tabular}{|ccccc|}
\hline $\begin{array}{c}\text { History of DM- } \\
\text { Duration }\end{array}$ & Group I & Group II & Group III & Total \\
$1-10$ & $43(71.7 \%)$ & $41(68.3 \%)$ & $49(81.7 \%)$ & $\mathbf{1 3 3}(\mathbf{7 3 . 9} \%)$ \\
$11-20$ & $10(16.7 \%)$ & $18(30 \%)$ & $11(18.3 \%)$ & $\mathbf{3 9}(\mathbf{2 1 . 7} \%)$ \\
$21-30$ & $2(3.3 \%)$ & $0(0 \%)$ & $0(0 \%)$ & $\mathbf{2}(\mathbf{1 . 1} \%)$ \\
Newly & $5(8.3 \%)$ & $1(1.7 \%)$ & $0(0 \%)$ & $\mathbf{6 ( 3 . 3 \% )}$ \\
Total & $\mathbf{6 0}(\mathbf{1 0 0} \%)$ & $\mathbf{6 0}(100 \%)$ & $\mathbf{6 0}(\mathbf{1 0 0} \%)$ & $\mathbf{1 8 0}(\mathbf{1 0 0} \%)$ \\
\hline Table 3. History of DM-Duration Distribution in Three Groups of \\
Patients Studied \\
\hline $\mathrm{P}=0.027 *$, Significant, Fisher Exact Test \\
\hline
\end{tabular}

Table 4 shows mean BMI $\left(\mathrm{kg} / \mathrm{m}^{2}\right)$ in Group 1, 2 \& 3 as $26.52,26.97 \& 26.67$ respectively, which was statistically not significant $(\mathrm{P}=0.711$, Not Significant, Student t test).

\begin{tabular}{|ccccc|}
\hline BMI (kg / m & Group I & Group II & Group III & Total \\
$<18.5$ & $0(0 \%)$ & $0(0 \%)$ & $0(0 \%)$ & $0(0 \%)$ \\
$18.5-25$ & $20(33.3 \%)$ & $17(28.3 \%)$ & $18(30 \%)$ & $55(30.6 \%)$ \\
$25-30$ & $32(53.3 \%)$ & $36(60 \%)$ & $34(56.7 \%)$ & $102(56.7 \%)$ \\
$>30$ & $8(13.3 \%)$ & $7(11.7 \%)$ & $8(13.3 \%)$ & $23(12.8 \%)$ \\
Total & $\mathbf{6 0}(100 \%)$ & $\mathbf{6 0}(100 \%)$ & $\mathbf{6 0}(100 \%)$ & $\mathbf{1 8 0}(100 \%)$ \\
Mean \pm SD & $26.52 \pm 3.33$ & $26.97 \pm 2.78$ & $26.67 \pm 3.02$ & $26.72 \pm 3.04$ \\
\hline Table 4. BMI $\left(\mathbf{k g} / \mathbf{m}^{2}\right)$ Distribution in Three Groups of Patients Studied \\
\hline P = 0.711, Not Significant, Student t test
\end{tabular}

It is evident from Table 5 that patients belonging to Group 3 had poor glycaemic control as reflected by the $\mathrm{HbA}_{1} \mathrm{C}$ values. $85 \%$ of patients in Group 3 had their mean $\mathrm{HbA}_{1} \mathrm{C}$ more than $9 \%, 78.3 \%$ of Group 2 patients had their mean $\mathrm{HbA}_{1} \mathrm{C}$ more than $9 \%$, whereas in Group 1 only $61.7 \%$ of the patients had their mean $\mathrm{HbA}_{1} \mathrm{C}$ more than $9 \%$, The above results being statistically significant $\left(\mathrm{P}-\right.$ Value $=0.003^{* *}$ chisquare / Fisher Exact Test).

FBS and PPBS values among the three groups had similar distribution and were not statistically significant.

\begin{tabular}{|c|c|c|c|c|c|}
\hline Variables & $\begin{array}{l}\text { Group I } \\
(\mathrm{N}=60)\end{array}$ & $\begin{array}{l}\text { Group II } \\
(\mathrm{N}=60)\end{array}$ & $\begin{array}{l}\text { Group III } \\
(\mathrm{N}=60)\end{array}$ & $\begin{array}{l}\text { Total } \\
(\mathrm{N}=180)\end{array}$ & P Value \\
\hline \multicolumn{6}{|l|}{ FBS (mg / dl) } \\
\hline$<90$ & $2(3.3 \%)$ & $1(1.7 \%)$ & $0(0 \%)$ & $3(1.7 \%)$ & \multirow{3}{*}{0.774} \\
\hline $90-120$ & $0(0 \%)$ & $0(0 \%)$ & $0(0 \%)$ & $0(0 \%)$ & \\
\hline$>120$ & 58 (96.7 \%) & $59(98.3 \%)$ & $60(100 \%)$ & $177(98.3 \%)$ & \\
\hline \multicolumn{6}{|l|}{ PPBS (mg / dl) } \\
\hline$<140$ & & & & & \multirow{3}{*}{1.000} \\
\hline $140-200$ & $3(5$ & $3(5$ & $2(3.3 \%)$ & $8(4.4 \%)$ & \\
\hline$>200$ & $57(95 \%)$ & $57(95 \%)$ & 58 (96.7\%) & $172(95.6 \%)$ & \\
\hline \multicolumn{6}{|l|}{ HbA1c \% } \\
\hline$<6$ & $2(3.3 \%)$ & $1(1.7 \%)$ & $4(6.7 \%)$ & $7(3.9 \%)$ & \multirow{3}{*}{$0.003^{* *}$} \\
\hline $6-9$ & $21(35 \%)$ & $12(20 \%)$ & $5(8.3 \%)$ & $38(21.1 \%)$ & \\
\hline$>9$ & $37(61.7 \%)$ & $47(78.3 \%)$ & $51(85 \%)$ & $135(75 \%)$ & \\
\hline \multicolumn{6}{|c|}{$\begin{array}{c}\text { Table 5. Sugar Parameter Distribution in Three Groups of Patients } \\
\text { Studied }\end{array}$} \\
\hline
\end{tabular}


Table 5 shows that radiological abnormality was more prevalent in Group 3 patients as compared to the other two groups and was less common in Group 1 patients as hypothesised.

As we see in Table 6 that bone and joint abnormality was more common in the patients with diabetic neuropathy with foot ulceration (83.3 \%).

\begin{tabular}{|c|c|c|c|c|}
\hline X-Ray & $\begin{array}{l}\text { Group I } \\
(N=60)\end{array}$ & $\begin{array}{l}\text { Group II } \\
(N=60)\end{array}$ & $\begin{array}{l}\text { Group III } \\
(N=60)\end{array}$ & $\begin{array}{c}\text { Total } \\
(\mathrm{N}=180)\end{array}$ \\
\hline Normal & $47(78.3 \%)$ & $30(50 \%)$ & $10(16.7 \%)$ & $87(48.3 \%)$ \\
\hline Abnormal & $13(21.7 \%)$ & $30(50 \%)$ & $50(83.3 \%)$ & $93(51.7 \%)$ \\
\hline $\begin{array}{l}\text { Osteopenia with osteoporotic } \\
\text { changes }\end{array}$ & $6(10 \%)$ & $10(16.7 \%)$ & $22(36.7 \%)$ & $38(21.1 \%)$ \\
\hline Vascular calcifications & $4(6.7 \%)$ & $10(16.7 \%)$ & $16(26.7 \%)$ & $30(16.7 \%)$ \\
\hline Osteopenia & $0(0 \%)$ & $6(10 \%)$ & $4(6.7 \%)$ & $10(5.6 \%)$ \\
\hline $\begin{array}{l}\text { Periosteal reaction in 2,3,4th } \\
\text { metatarsals }\end{array}$ & $1(1.7 \%)$ & $0(0 \%)$ & $4(6.7 \%)$ & $5(2.8 \%)$ \\
\hline Osteoporotic changes & $1(1.7 \%)$ & $2(3.3 \%)$ & $0(0 \%)$ & $3(1.7 \%)$ \\
\hline $\begin{array}{l}\text { Subluxation of } 2,3,4 \text { and } 5 \text { th } \\
\text { metatarsals }\end{array}$ & $0(0 \%)$ & $0(0 \%)$ & $2(3.3 \%)$ & $2(1.1 \%)$ \\
\hline $\begin{array}{l}\text { All bones osteopenia,5th } \\
\text { metatarsophalengeal pencil cup } \\
\text { deformity }\end{array}$ & $0(0 \%)$ & $0(0 \%)$ & $1(1.7 \%)$ & $1(0.6 \%)$ \\
\hline Calcaneal spur & $0(0 \%)$ & $0(0 \%)$ & $1(1.7 \%)$ & $1(0.6 \%)$ \\
\hline Osteopenia pharyngeal bones & $1(1.7 \%)$ & $0(0 \%)$ & $0(0 \%)$ & $1(0.6 \%)$ \\
\hline Osteosclerosis & $0(0 \%)$ & $1(1.7 \%)$ & $0(0 \%)$ & $1(0.6 \%)$ \\
\hline Periosteal erosions & $0(0 \%)$ & $1(1.7 \%)$ & $0(0 \%)$ & $1(0.6 \%)$ \\
\hline \multicolumn{5}{|c|}{ Table 6. X-Ray } \\
\hline
\end{tabular}

The most common abnormality observed from our study was osteopenia with osteoporotic changes seen in $36.7 \%$ of Group III patients vs. $16.7 \%$ of Group II and only in $10 \%$ of Group I patients. Vascular calcifications were observed in $26.7 \%$ VS 16.7 \% VS 6.7 \% in Group III, Group II, Group I respectively. Periosteal reactions were also more common in Group III patients (6.7\%). Metatarsal subluxation of 2, 3, 4, and $5^{\text {th }}$ were observed only in $3.3 \%$ of Group III patients. Pencil cup deformity (1.7 \%) and calcaneal spur (1.7\%) was observed in only one patient in Group III. Osteoporotic changes were more common in Group II patients as compared to others. Periosteal erosion was seen in only one patient of Group II.

\section{DISCUSSION}

In the present study, we observed that there was no difference in the incidence of diabetes and associated complications among males and females. We also observed from our study that diabetic individuals with neuropathy and with both neuropathy and foot ulcers were older than those without these complications which were in accordance with several other studies.

The study conducted on the risk factors of diabetic foot ulcers by Leila Y, Hajieh S, Iraj N, Hamid R A, Fatemeh A, Bahman $\mathrm{C}^{26}$ et al. found the incidence of diabetic foot ulcers to be $2.8 \%$ and previous history of diabetic foot ulcer or amputation, use of insulin, duration of diabetes, glycaemic control, distal neuropathy and foot deformity as significant risk factors. This was similar to our study where diabetic patients with both neuropathy and foot ulceration had a relatively longer duration of diabetes, poor glycaemic control and had a higher prevalence of radiological foot abnormalities.

A study by Shailesh K. S, Ashok K, Sushil K, Surya K. S, Sanjeev K. G, Singh T B ${ }^{27}$ found the prevalence of diabetic foot ulcers to be $14.30 \%$. This percentage is worrisome to a country like India. In our study, there was no correlation between BMI and foot complications of diabetes. Also, our study in accordance with various other studies showed a positive correlation between duration of diabetes and foot complications.

A study done by Douglas G. S, Brett C. B, Andrew K. S, Edward J. B, Jessie H. $A^{28}$ et al. on the prevalence of radiographic foot abnormalities in patients with diabetes revealed various foot abnormalities like arterial calcification, MTP joint dislocation, Charcot joint, Hallux IP dislocation and others. In their study arterial calcification was most prevalent. The present study also revealed similar radiological foot abnormalities.

Several studies done previously have concluded that diabetic patients have decreased cortical bone mass in comparison to normal individuals. ${ }^{29,30}$ Our present study supported the above observation as we could see Osteopenia with osteoporotic changes in $36.7 \%$ of diabetic patients with both neuropathy and foot ulceration and $16.7 \%$ of diabetic patients with neuropathy as opposed to only $10 \%$ in diabetic patients without any abnormality.

We could also infer from our study that the onset of neuropathy is an important predisposing factor for the development of foot complications, hence all diabetic patients must be carefully assessed clinically for the presence of neuropathy which can potentially prevent the development of several complications.

We could observe from our study that a maximum number of abnormalities such as Subluxation, periosteal reactions and osteopenia were seen in diabetic patients with both neuropathy and foot ulceration. Preventing the diabetic foot should be the priority. This can be achieved by identifying the high-risk individuals like those with peripheral neuropathy, peripheral vascular disease, foot deformities, or presence of callus. ${ }^{31}$

\section{CONCLUSIONS}

Diabetic foot is one of the most devastating complications of diabetes. In India, the scenario is quite demoralizing mainly because of lack of education, ignorance on the part of primary physicians and diabetic patients, barefoot walking, late reporting after the initial trauma and continued use of tobacco. Preventing the diabetic foot should be the first priority. This can be achieved by identifying the high-risk individuals with the above said risk factors by proper clinical examination and use of foot X-ray.

\section{Limitations of the Present Study \\ - Smaller sample size \\ - Observational nature of the study}

Data sharing statement provided by the authors is available with the full text of this article at jemds.com.

Financial or other competing interests: None.

Disclosure forms provided by the authors are available with the full text of this article at jemds.com. 
The help rendered by Dr Vedaraju, professor of Radiology, BMCRI is greately acknwledged.

\section{REFERENCES}

[1] Caputo GM, Cavanagh PR, Ulbrecht JS, et al. Assessment and management of foot disease in patients with diabetes. N Engl J Med 1994;331(13):854-60.

[2] Hurt RD, Offord KP, Croghan IT, et al. Mortality following inpatient addictions treatment: Role of tobacco use in a community-based cohort. JAMA 1996;275(14):1097103.

[3] Lisha NE, Carmody TP, Humfleet GL, et al. Reciprocal effects of alcohol and nicotine in smoking cessation treatment studies. Addict Behav 2014;39(3):637-43.

[4] Dietrich I, Braga GA, De Melo FG, et al. The diabetic foot as a proxy for cardiovascular events and mortality review. Curr Atheroscler Rep 2017;19(11):44.

[5] Petrova NL, Foster AVM, Edmonds ME. Difference in presentation of charcot osteoarthropathy in type 1 compared with type 2 diabetes. Diabetes Care 2004;27(5):1235-6.

[6] Stuck RM, Sohn MW, Budiman-Mak E, et al. Charcot arthropathy risk elevation in the obese diabetic population. Am J Med 2008;121(11):1008-14.

[7] Krukowski RA, Solomon LJ, Naud S. Triggers of heavier and lighter cigarette smoking in college students. J Behav Med 2005;28(4):335-45.

[8] Pham H, Armstrong DG, Harvey C, et al. Screening techniques to identify people at high risk for diabetic foot ulceration: a prospective multicenter trial. Diabetes Care 2000;23(5):606-11.

[9] Andersen H, Gadeberg PC, Brock B, et al. Muscular atrophy in diabetic neuropathy: a stereological magnetic resonance imaging study. Diabetologia 1997;40(9):1062-9.

[10] Sharkey NA, Donahue SW, Ferris L. Biomechanical consequences of plantar fascial release or rupture during gait. Part II: alterations in forefoot loading. Foot Ankle Int 1999;20(2):86-96.

[11] Siitonen OI, Niskanen LK, Laakso M, et al. Lowerextremity amputations in diabetic and nondiabetic patients: a population-based study in Eastern Finland. Diabetes Care 1993;16(1):16-20.

[12] Trautner C, Haastert B, Giani G, et al. Incidence of lower limb amputations and diabetes. Diabetes Care 1996;19(9):1006-9.

[13] Reiber GE. The epidemiology of diabetic foot problems. Diabet Med 1996;13(Suppl 1):S6-11.

[14] International Working Group on the Diabetic Foot Epidemiology of diabetic foot infections in a population based cohort. International Consensus on the Diabetic Foot 2003;5:22-4.

[15] Armstrong D, Lavery L, Quebedeaux T, et al. Surgical morbidity and the risk of amputation due to infected puncture wounds in diabetic versus nondiabetic adults. J Am Podiatr Med Assoc 1997;87(7):321-6.

[16] Reiber GE, Ledoux WR. Epidemiology of diabetic foot ulcers and amputations: evidence for prevention. The Evidence Base for Diabetes Care 2002:641-65.

[17] Iversen MM, Tell GS, Riise T, et al. History of foot ulcer increases mortality among individuals with diabetes: ten-year follow-up of the Nord-Trøndelag health study, Norway. Diabetes Care 2009;32(12):2193-9.

[18] Banerjee B, Das RK. Sonographic detection of foreign bodies of the extremities. Br J Radiol 1991;64(758):10712.

[19] Cavanagh PR, Young MJ, Adams JE, et al. Radiographic abnormalities in the feet of patients with diabetic neuropathy. Diabetes Care 1994;17(3):201-9.

[20] Palestro CJ, Torres MA. Radionuclide imaging in orthopedic infections. Semin Nucl Med 1997;27(4):33445.

[21] American Diabetes Association. Diagnosis and classification of diabetes mellitus. Diabetes Care 2014;37(Suppl 1):S81-90.

[22] Rosner B. Fundamentals of biostatistics. $5^{\text {th }}$ edn. Duxbury 2000:80-240.

[23] Riffenburg RH. Statistics in medicine. $2^{\text {nd }}$ edn. Academic Press 2005:85-125.

[24] Rao PSSS, Richard J. An introduction to biostatistics. A manual for students in health sciences. New Delhi: Prentice hall of India. $4^{\text {th }}$ edn. 2006:86-160.

[25] Suresh KP, Chandrasekhar S. Sample size estimation and power analysis for clinical research studies. J Hum Reprod Sci 2012;5(1):7-13.

[26] Yazdanpanah L, Shahbazian H, Nazari I, et al. Incidence and risk factors of diabetic foot ulcer: a population-based diabetic foot cohort (ADFC Study)-two-year follow-up study. Int J Endocrinol 2018;2018:7631659.

[27] Shahi SK, Kumar A, Kumar S, et al. Pevalance of diabetic foot ulcer and associated risk factors in diabetic patients from North India. Journal of Diabetic Foot Complications 2012;4(3):83-91.

[28] Smith DG, Barnes BC, Sands AK, et al. Prevalence of radiographic foot abnormalities in patients with diabetes. Foot Ankle Int 1997;18(6):342-6.

[29] Buysschaert M, Cauwe F, Jamart J, et al. Proximal femur density in type 1 and 2 diabetic patients. Diabet Metab 1992;18(1):32-7.

[30] Petit MA, Paudel ML, Taylor BC, et al. Bone mass and strength in older men with type 2 diabetes: the osteoporotic fractures in men study. J Bone Mineral Res 2010;25(2):285-91.

[31] Apelqvist J, Bakker $K$, Van Houtum WH, et al. International consensus and practice guidelines on manage ment and the prevention of the diabetic foot. International working group on the diabetic foot. Diabetes Metab Res Rev 2000;16(Suppl 1):S84-92. 